\title{
Neocortical calretinin neurons in primates: increase in proportion and microcircuitry structure
}

\author{
Domagoj Džaja ${ }^{1}$, Ana Hladnik ${ }^{2}$, Ivana Bičanić ${ }^{2}$, Marija Baković ${ }^{3}$ and Zdravko Petanjek ${ }^{1,2}$ \\ ' Laboratory for Neuromorphometry, Department of Neuroscience, Croatian Institute for Brain Research, School of Medicine, University of Zagreb, Zagreb, \\ Croatia \\ 2 Department of Anatomy and Clinical Anatomy, School of Medicine, University of Zagreb, Zagreb, Croatia \\ ${ }^{3}$ Institute of Forensic Medicine and Criminalistics, School of Medicine, University of Zagreb, Zagreb, Croatia
}

Edited by:

Nada Zecevic, University of

Connecticut Health Center, USA

Reviewed by:

Gundela Meyer, Universidad de La

Laguna, Spain

Srdjan D. Antic, University of

Connecticut Health Center, USA

${ }^{*}$ Correspondence:

Domagoj Džaja, Laboratory for

Neuromorphometry, Department of Neuroscience, Croatian Institute for Brain Research, School of Medicine, University of Zagreb, Šalata 12,

10000 Zagreb, Croatia

e-mail:domagojdzaja@gmail.com
In this article we first point at the expansion of associative cortical areas in primates, as well as at the intrinsic changes in the structure of the cortical column. There is a huge increase in proportion of glutamatergic cortical projecting neurons located in the upper cortical layers (II/III). Inside this group, a novel class of associative neurons becomes recognized for its growing necessity in both inter-areal and intra-areal columnar integration. Equally important to the changes in glutamatergic population, we found that literature data suggest a $50 \%$ increase in the proportion of neocortical GABAergic neurons between primates and rodents. This seems to be a result of increase in proportion of calretinin interneurons in layers $\| / I I$, population which in associative areas represents $15 \%$ of all neurons forming those layers. Evaluating data about functional properties of their connectivity we hypothesize that such an increase in proportion of calretinin interneurons might lead to supra-linear growth in memory capacity of the associative neocortical network. An open question is whether there are some new calretinin interneuron subtypes, which might substantially change micro-circuitry structure of the primate cerebral cortex.

Keywords: GABA, calretinin, neocortex, pyramidal neurons, species differences

\section{INTRODUCTION}

The main biological substrate for mammalian mental abilities is the neuronal circuitry of the cerebral cortex. Tremendous evolutionary increase in the neuron number and cortical connections (DeFelipe, 2011; Charvet and Finlay, 2012) allowed humans to adopt language and mathematical skills, to make affective modulation of emotional cues, possess self-conceptualization, mentalization, as well as to have high capacity of cognitive flexibility and working memory (Rakic, 2009). Such complex functioning is strongly related to distinct expansion of multimodal - high order associative areas, particularly the granular areas of the frontal lobe (i.e., associative prefrontal cortex; Teffer and Semendeferi, 2012). These areas have no clear correlate in mice and rats (Uylings and van Eden, 1990). In addition to expansion in size, there are significant changes in intrinsic organization of cortical circuitries (Figure 1). There are novel neuronal elements that appear in the human cerebral cortex making organization of microcircuitry (and consequently functional properties) substantially different when compared to non-primate mammals (Clowry et al., 2010).

In this article we first give a short overview of evolutionary changes in the connectivity of a specific class of principal (glutamatergic) cortico-cortical projecting neurons, as well as a possible functional significance of those changes regarding increase in cognitive capabilities. We also found that present comparative anatomical data suggest a distinct role in reorganization of cortical microcircuitry for one of the GABAergic local circuit neuron classes, the calretinin expressing neurons that in primates have much higher proportion. We propose a possible mechanism how calretinin neurons might contribute to reorganization of microcircuitry in the human associative cortex and how this might be related to an increase of cognitive capabilities.

\section{MICROCIRCUITRY CHANGES IN THE PRIMATE PREFRONTAL CORTEX AND INCREASE IN PROPORTION OF CALRETININ NEURONS}

It is well recognized that upper layer pyramids (DeFelipe, 2011; Shepherd, 2011; Teffer and Semendeferi, 2012) are corticocortical projecting neurons (Elston et al., 2011; DeFelipe et al., 2012). It is less recognized that in primates, large deep layer III pyramids are long distance cortico-cortical neurons which establish in parallel connections with several cortical areas (Barbas etal., 2005; Yeterian et al., 2012). Experimental studies in rhesus monkey show that they are key elements in the circuitry involved in working memory and other prefrontal cortex-dependent associative cognitive functions (Wang etal., 2006; Verduzco-Flores et al., 2009). Data from various psychiatric disorders showed that selective alteration of large layer III pyramidal cells correlates with a decline in higher cognitive functions (Morrison and Hof, 2002; Selemon et al., 2003; Dean, 2009; Dorph-Petersen etal., 2009; Courchesne etal., 2011; Jacot-Descombes et al., 2012; Teffer and Semendeferi, 2012; Selemon etal., 2013) and developmental studies found that prominence in size of neurons in the upper cortical layers and peak in synaptic number appear by the end of infancy, stage when human specific mental capacities appear (Petanjek et al., 2008, 2011). Altogether, it can be concluded that large layer III pyramidal neurons in the high order associative areas are the main integrative 


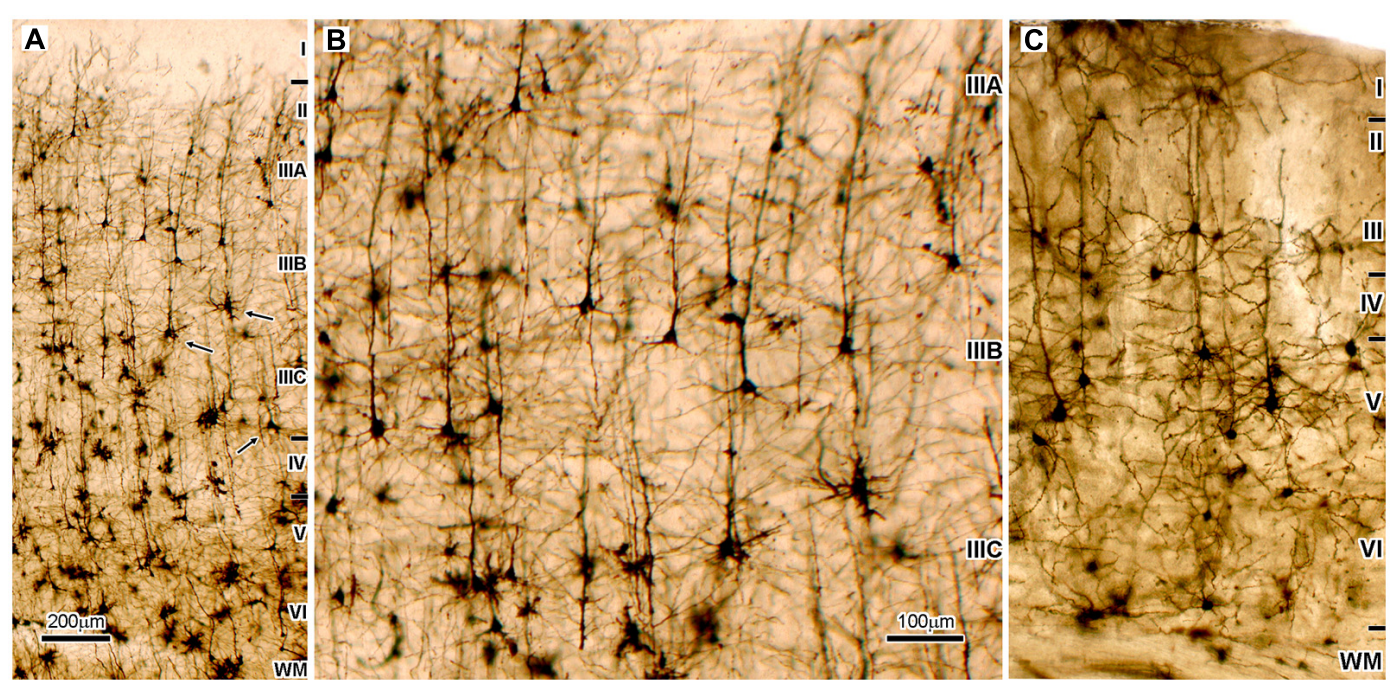

FIGURE 1 | Microphotography of the Golgi Cox impregnated sections of the associative areas in the human $(A, B)$ and mice neocortex (C). (A) Dorso-lateral part of the frontal granular cortex (area 9) shows that supragranular cortical layers (II/III), which contain cortical projecting neurons, are two times thicker than infragranular layers (VNI), which contain subcortical projecting neurons. In addition, pyramidal neurons (arrows) located deep inside layer III (sublayer IIIC) have largest cell body as well as most complex and extended dendritic arborization. Therefore they are the most prominent neurons found on Golgi staining, and on the Nissl staining they produce distinct cytoarchitectonic feature found only in high order associative areas of the cerebral cortex of human and apes, the magnocellularity (magnopyramidality) of the layer III (Petrides etal., 2012). Those neurons are on Nissl stained sections not only prominent by cell body size, they also have most intense cytoplasmatic staining showing high metabolic activity (Rajkowska and Goldman-Rakic, 1995a). They also have the most intense SMI32 staining, that indicates a very long and ramified axon tree (Morrison and Hof, 2002). The mentioned morphological features are a mark of associative cortico-cortical neurons. (B) Enlarged part of panel (A) is shown to be of the same magnification as panel (C). (C) The highest order associative areas in the mice neocortex are located in the parieto-occipital region. When compared to highest order associative areas of the human neocortex $(\mathbf{A}, \mathbf{B})$ proportion of cortico-cortical projecting neurons is smaller than cortico-subcortical projecting neurons, and the largest neurons are layer $\mathrm{V}$ pyramids. Therefore, thickness of layers $\|/\| \|$ in mice is less than half of the thickness of layers VNI, which is opposite to human. In the parasensory associative areas (that do not have developed sublayer IIIC) of the human temporal cortex, layers II/III contain $44 \%$ of total number of neurons and have $30 \%$ more neurons than are located in layers VNI (DeFelipe, 2011). It can be assumed that in areas with developed layer IIIC upper cortical layers contain more than $50 \%$ of neurons. In mice, upper cortical layers contain only $22 \%$ of neurons that is less than half of amount located in layers VNI. elements ("associative" neurons) between different cortical areas (Goldman-Rakic, 1999; see discussion from Petanjek et al., 2008).

Pyramidal neurons located in upper layers of the primate prefrontal cortex also provide rich intracortical projections. From large layer III pyramids $80 \%$ of synaptic output belongs to local connections coming from axonal side branches (Melchitzky and Lewis, 2003). They extend several millimeters around, with dense columnar termination through layers II and III.

Human brain evolution is characterized by an increase in the number and width of minicolumns, but also in the increase of space available for interconnectivity between neurons, especially in the human prefrontal cortex where associative layer III pyramidal neurons are particularly abundant (DeFelipe etal., 2012; Spocter etal., 2012). Except to primary regions, prefrontal cortex established connections with all other cortical areas (Groenewegen and Uylings, 2000). That way efficacy of interand intra-areal integration within prefrontal cortex correlates with overall level of information processing, influencing consequently level of individual cognitive capability (Petanjek and Kostovic, 2012). Inter-individual differences in internal structure of upper cortical layers of human prefrontal cortex (Rajkowska and Goldman-Rakic, 1995a,b) make additional support that associative layer III neuron class has the major role in increasing the efficiency of cortico-cortical network (Buckner and Krienen, 2013; Hofman, 2014).

In parallel with evolutionary changes in connectivity of corticocortical network, significant changes appear in the organization of GABAergic network. This network acts as intrinsic modulator of cortical output since it is composed of local circuit neurons (interneurons; DeFelipe et al., 2013). Numerous studies analyzing laminar distribution and density of cortical GABAergic neuron subpopulations were performed in various species (Table 1A). It is curious that only rarely the same group performed a systematic analysis of several species, using the same methodology, making it difficult to conclude about interspecies differences. Most of the studies performed in rat and mouse found that cortical GABAergic neurons represent around 15\% (14-16\%) of the overall population. In monkey and human their proportion mostly exceeds 20\% (20-29\%) suggesting an increase in proportion for about $30-50 \%$.

This large increase in proportion of GABAergic neurons seems to be principally caused by increase in number of neurons containing calretinin. Another two main classes, those containing parvalbumin and somatostatin, do not show such a robust increase in proportion (Hladnik et al., 2014). In rodents the proportion of calretinin neurons among the total population of GABAergic 
Table 1 | Overview of publications quantifying proportion of GABAergic and calretinin neurons in the neocortex of rodents and primates.

(A) Proportion of GABAergic cells in population of all neurons, and (B) proportion of calretinin neurons inside the GABAergic population.

(A) Percentage of GABAergic cells in the total neuron population

\begin{tabular}{|c|c|c|}
\hline Anatomical area & Rat and mouse - GABA in total & Monkey and human - GABA in total \\
\hline Primary visual area (V1) & $\begin{array}{l}\text { 15\% (Beaulieu etal., 1994) - Rat } \\
\text { 14.5\% (Meinecke and Peters, 1987) - Rat } \\
\text { 15\% (Lin etal., 1986) - Rat }\end{array}$ & $\begin{array}{l}\text { 20.5\% (Beaulieu etal., 1992) - Monkey } \\
\text { 15\% (Fitzpatrick et al., 1987) - Monkey } \\
\text { 20\% (Hendry et al., 1987) - Monkey }\end{array}$ \\
\hline $\begin{array}{l}\text { Primary somatic sensory } \\
\text { area (S1) }\end{array}$ & $\begin{array}{l}\text { 14\% (Micheva and Beaulieu, 1995) - Rat } \\
\text { 25\% (Ren et al., 1992) - Rat }\end{array}$ & 20-29\% (Jones et al., 1994) - S1 and primary motor area-Monkey \\
\hline Temporal lobe & & 37.7\% (del Rio and DeFelipe, 1996) - only layers II and III-Human \\
\hline Multiple lobe analysis & $\begin{array}{l}\text { 19.5\% (Tamamaki et al., 2003) - Mouse } \\
\text { 15\% (Beaulieu, 1993) - Rat }\end{array}$ & 25\% (Hendry et al., 1987) \\
\hline
\end{tabular}

(B) Percentage of calretinin expressing neurons within GABAergic population

\begin{tabular}{|c|c|c|}
\hline Anatomical area & Rat and mouse - calretinin in GABA & Monkey and human - calretinin in GABA \\
\hline Primary visual area (V1) & $\begin{array}{l}\text { 17\% (Gonchar and Burkhalter, 1997) - Rat } \\
24 \% \text { (Gonchar et al., 2007) - Mouse }\end{array}$ & 20\% (Yan et al., 1995) - Monkey \\
\hline Frontal lobe & $\begin{array}{l}\text { 16.1\% (Uematsu etal., 2008) - Rat } \\
24.7 \% * \text { (Gabbott etal., 1997) - Rat }\end{array}$ & $\begin{array}{l}\text { 28.6\% (Zaitsev et al., 2005) - Monkey } \\
28.8 \% \text { * - Human } \\
34.2 \% \text { * - Monkey (Sherwood etal., 2004) }\end{array}$ \\
\hline & 18\% (Kubota et al., 1994) - Rat & $\begin{array}{l}\text { 33.2-44.8\%* (Gabbott and Bacon, 1996; Meskenaite, 1997; } \\
\text { Melchitzky etal., 2005)* - Monkey }\end{array}$ \\
\hline Temporal lobe & & 46.2\% (del Rio and DeFelipe, 1996) - only layers II and III-Human \\
\hline Multiple lobe analysis & $\begin{array}{l}\text { 18\% (Xu etal., 2010) - Mouse } \\
13.9 \% \text { (Tamamaki et al., 2003) - Mouse }\end{array}$ & \\
\hline
\end{tabular}

Values reported with an asterisk have been calculated from values presented in the original papers.

neurons is between $16-18 \%$, whereas in primate the proportion of calretinin reaches in some areas $35-40 \%$ (Table 1B). del Rio and DeFelipe (1996) have estimated that, within layer II and III of associative temporal cortex in the human, GABAergic neurons represent around $1 / 3$ of the total number of neurons, and almost half of GABAergic neurons express calretinin. In addition, a recent study (Ma et al., 2013) suggests that, in the human and monkey, calretinin neurons are two times more numerous in the frontal and parietal cortical areas. Collectively all these data indicate that the evolution lead to an increase in calretinin proportion in the upper cortical layers of high order associative regions. Our preliminary observations, comparing orbital frontal cortex in the rat and complementary area 14 in the rhesus monkey, showed a fourto fivefold increase in the proportion of calretinin for the upper cortical layers, where calretinin neurons cover almost $15 \%$ of the total number of neurons (Džaja et al., 2014).

\section{FUNCTIONAL PROPERTIES OF CALRETININ NEURONS}

For efficient functioning of the human cerebral cortex with its complex areal subdivision and increased number of cortical columns, there is a need for enhanced inter-areal and intra-areal integration (Sherwood et al., 2005; Hofman, 2014). Appearance of most likely, evolutionary new associative neurons (DeFelipe and Fariñas, 1992; Nieuwenhuys, 1994; Spruston, 2008) makes substantial changes in the organization of microcircuitry and allows higher level of network integration (Buckner and Krienen, 2013). Inside the primate cortico-cortical network there is also a fivefold increase in proportion of calretinin neurons and it is reasonable to ask how this changes the microcircuitry structure.

Based on electrophysiological properties, two main types of calretinin interneurons can be distinguished in rodents: accommodating and non-adapting non-fast spiking cells (Markram et al., 2004; Butt et al., 2005; Caputi et al., 2009). These electrophysiological features are correlated with expression of a group of membrane voltage gated proteins (Markram et al., 2004), the calretinin cluster (Toledo-Rodriguez et al., 2004; Schwaller, 2014).

Different types of calretinin neurons can be identified based on their morphological features, particularly on the postsynaptic domain targeted by their axon. Double bouquet cells have vertically oriented axons which project mainly to basal dendrites of pyramidal cells (del Rio and DeFelipe, 1995; Yanez et al., 2005), while bipolar (Peters and Kimerer, 1981) and bitufted 
cells (Jiang etal., 2013) project to the proximal and middle region of pyramidal cell's apical dendrite. Therefore, calretinin neurons provide direct inhibition, although with a low connectivity rate of $\sim 10 \%$ (Caputi et al., 2009), on mid-proximal dendritic domain of pyramidal cell (i.e., proximal parts of apical and basal dendrites). In addition to this sparse connectivity with nearby pyramids, calretinin neurons provide strong innervation onto somatostatin neurons (Pfeffer et al., 2013) and other calretinin cells (Caputi et al., 2009). These somatostatin neurons are known for providing direct inhibition of pyramidal cell's apical and basal dendrites (Wang et al., 2004; Jiang et al., 2013), as well as for providing an inhibitory influence on parvalbumin neurons (Pfeffer et al., 2013).

Parvalbumin neurons are mostly basket cells, which exert strong inhibitory control over pyramid's soma (Markram et al., 2004; Pfeffer et al., 2013). Optogenetic activation of fast spiking parvalbumin cells induces gamma oscillations in nearby pyramids (Cardin et al., 2009) and, without parvalbumin activity, pyramids would continue to fire but without synchrony (Gulyas et al., 2010). In other words, parvalbumin basket cells phaselock their target pyramids through hyperpolarization, after which pyramids undergo rebound, but short lived depolarization and fire in synchrony (Cobb et al., 1995). Elimination of inhibitory influences on parvalbumin basket cells prolongs their influence on pyramids (Pouille and Scanziani, 2004), and this is where the potential role of calretinin neurons could reside. By inhibiting somatostatin neurons (Pfeffer et al., 2013; Cauli et al., 2014) they could create a disinhibitory window for parvalbumin baskets. We hypothesize that this, by calretinin neurons provided disinhibition, might prolong the effect of parvalbumin cells on pyramids, allowing longer periods of synchronized gamma oscillations.

This group of cells, including calretinin neurons, their somatostatin targets, parvalbumin neurons, and their pyramidal targets, can be collectively called a neuronal assembly (Borgers et al., 2012; Somogyi et al., 2014). The significance of an assembly is that it can activate its efferent targets with high probability, through the synchronous activity of its pyramids (Harris et al., 2003; Buzsaki and Wang, 2012). Interneurons are needed to segregate, maintain and also establish a temporal sequence of activation between particular assemblies (Somogyi et al., 2014). We hypothesize that the role of increased proportion of calretinin neurons would depend on the criteria of their territorial exclusivity, i.e., their developmental positioning to efferent targets compared to other calretinin interneurons. If newly added calretinin cells show no territorial exclusivity, i.e., their connections significantly overlap with those of pre-existent calretinin neurons, they would be incorporated into already established assemblies, connecting to somatostatin neurons to which some calretinin neurons have previously connected. Hence, there would be an increased number of calretinin cells per assembly, while the number of pyramids would not change, allowing for a more potent overall effect of calretinin neurons. However, in case of the other extreme, newly added calretinin cells will mostly connect to their own group of pyramids and parvalbumin and somatostatin neurons, creating smaller assemblies and allowing for more parallel processing. More parallel units might lead to supra-linear growth in memory capacity of the neocortical network, which is of particular importance in regions involved in planning and executive functions.

Present evidence suggests that the evolutionary path of the primate cortico-cortical network seems to have been an expansion in two aspects. First, there is an increase in proportion of principal neurons located in layers II and III, which would be a way to create the basic excitatory architecture for inter-areal processing. Second, there is an increase in proportion of calretinin expressing GABAergic interneurons, which would be a way to create a gain in synchrony and parallel processing between disparate cortical areas. An open question is whether this jump in proportion of calretinin neurons is based on a simple expansion of already preexistent subtypes of these cells found in the rodents or do we have some new cellular subtypes. If so, this might produce a more profound changes then simple supra-linear increase in their number, similar to changes occurring with appearance of associative principal neurons. These two might have been converging processes, making structure of microcircuitry in the primate neocortex substantially different when compared to other non-primate mammals.

\section{ACKNOWLEDGMENTS}

We wish to thank Dr. Monique Esclapez and Prof. Marijan Klarica for helpful comments and discussions on this manuscript. This work was supported by the University of Zagreb short term grant "Prolonged proliferation of cortical GABAergic neurons in primates" and Croatian Science Foundation grant "Microcircuitry of higher cognitive functions."

\section{REFERENCES}

Barbas, H., Hilgetag, C. C., Saha, S., Dermon, C. R., and Suski, J. L. (2005). Parallel organization of contralateral and ipsilateral prefrontal cortical projections in the rhesus monkey. BMC Neurosci. 6:32. doi: 10.1186/1471-2202-6-32

Beaulieu, C. (1993). Numerical data on neocortical neurons in adult rat, with special reference to the GABA population. Brain Res. 609, 284-292. doi: 10.1016/00068993(93)90884-P

Beaulieu, C., Campistron, G., and Crevier, C. (1994). Quantitative aspects of the GABA circuitry in the primary visual cortex of the adult rat. J. Comp. Neurol.339, 559-572. doi: 10.1002/cne.903390407

Beaulieu, C., Kisvarday, Z., Somogyi, P., Cynader, M., and Cowey, A. (1992). Quantitative distribution of GABA-immunopositive and -immunonegative neurons and synapses in the monkey striate cortex (area 17). Cereb. Cortex 2, 295-309. doi: 10.1093/cercor/2.4.295

Borgers, C., Talei Franzesi, G., Lebeau, F. E., Boyden, E. S., and Kopell, N. J. (2012). Minimal size of cell assemblies coordinated by gamma oscillations. PLoS Comput. Biol. 8:e1002362. doi: 10.1371/journal.pcbi.1002362

Buckner, R. L., and Krienen, F. M. (2013). The evolution of distributed association networks in the human brain. Trends Cogn. Sci. 17, 648-665. doi: 10.1016/j.tics.2013.09.017.

Butt, S. J., Fuccillo, M., Nery, S., Noctor, S., Kriegstein, A., Corbin, J. G., et al. (2005). The temporal and spatial origins of cortical interneurons predict their physiological subtype. Neuron 48, 591-604. doi: 10.1016/j.neuron.2005.09.034

Buzsaki, G., and Wang, X. J. (2012). Mechanisms of gamma oscillations. Annu. Rev. Neurosci. 35, 203-225. doi: 10.1146/annurev-neuro-062111-150444

Caputi, A., Rozov, A., Blatow, M., and Monyer, H. (2009). Two calretinin-positive GABAergic cell types in layer $2 / 3$ of the mouse neocortex provide different forms of inhibition. Cereb. Cortex 19, 1345-1359. doi: 10.1093/cercor/bhn175

Cardin, J. A., Carlen, M., Meletis, K., Knoblich, U., Zhang, F., Deisseroth, K., et al. (2009). Driving fast-spiking cells induces gamma rhythm and controls sensory responses. Nature 459, 663-667. doi: 10.1038/nature08002

Cauli, B., Zhou, X., Tricoire, L., Toussay, X., and Staiger, J. F. (2014). Revisiting the enigmatic cortical calretinin-expressing interneurons. Front. Neuroanat. 8:52. doi: $10.3389 /$ fnana.2014.00052 
Charvet, C. J., and Finlay, B. L. (2012). Embracing covariation in brain evolution: large brains, extended development, and flexible primate social systems. Prog. Brain Res. 195, 71-87. doi: 10.1016/B978-0-444-53860-4.00004-0

Clowry, G., Molnár, Z., and Rakic, P. (2010). Renewed focus on the developing human neocortex. J. Anat. 217, 276-288. doi: 10.1111/j.1469-7580.2010.01281.x

Cobb, S. R., Buhl, E. H., Halasy, K., Paulsen, O., and Somogyi, P. (1995). Synchronization of neuronal activity in hippocampus by individual GABAergic interneurons. Nature 378, 75-78. doi: 10.1038/378075a0

Courchesne, E., Mouton, P. R., Calhoun, M. E., Semendeferi, K., AhrensBarbeau, C., Hallet, M. J., et al. (2011). Neuron number and size in prefrontal cortex of children with autism. JAMA 306, 2001-2010. doi: 10.1001/jama. 2011.1638

Dean, B. (2009). Is schizophrenia the price of human central nervous system complexity? Aust. N. Z. J. Psychiatry 43, 13-24. doi: 10.1080/00048670802534416

DeFelipe, J. (2011). The evolution of the brain, the human nature of cortical circuits, and intellectual creativity. Front. Neuroanat. 5:29. doi: 10.3389/fnana.2011.00029

DeFelipe, J., and Fariñas, I. (1992). The pyramidal neuron of the cerebral cortex: morphological and chemical characteristics of the synaptic inputs. Prog. Neurobiol. 39, 563-607. doi: 10.1016/0301-0082(92)90015-7

DeFelipe, J., Lopez-Cruz, P. L., Benavides-Piccione, R., Bielza, C., Larranaga, P., Anderson, S., et al. (2013). New insights into the classification and nomenclature of cortical GABAergic interneurons. Nat. Rev. Neurosci. 14, 202-216. doi: $10.1038 / \mathrm{nrn} 3444$

DeFelipe, J., Markram, H., and Rockland, K. S. (2012). The neocortical column. Front. Neuroanat. 6:22. doi: 10.3389/fnana.2012.00022

del Rio, M. R., and DeFelipe, J. (1995). A light and electron microscopic study of calbindin D-28k immunoreactive double bouquet cells in the human temporal cortex. Brain Res. 690, 133-140. doi: 10.1016/0006-8993(95) 00641-3

del Rio, M. R., and DeFelipe, J. (1996). Colocalization of calbindin D$28 \mathrm{k}$, calretinin, and GABA immunoreactivities in neurons of the human temporal cortex. J. Comp. Neurol. 369, 472-482. doi: 10.1002/(SICI)10969861(19960603)369:3<472::AID-CNE11>3.0.CO;2-K

Dorph-Petersen, K. A., Delevich, K. M., Marcsisin, M. J., Zhang, W., Sampson, A. R., Gundersen, H. J., et al. (2009). Pyramidal neuron number in layer 3 of primary auditory cortex of subjects with schizophrenia. Brain Res. 1285, 42-57. doi: 10.1016/j.brainres.2009.06.019

Džaja, D., Petanjek, Z., and Esclapez, M. (2014). “The orbitofrontal cortex: Higher density of calretinin interneurons in primates than in rodents," in Proceedings of the 9th FENS Forum of Neuroscience, Milan.

Elston, G. N., Benavides-Piccione, R., Elston, A., Manger, P. R., and Defelipe, J. (2011). Pyramidal cells in prefrontal cortex of primates: marked differences in neuronal structure among species. Front. Neuroanat. 5:2. doi: 10.3389/fnana.2011.00002

Fitzpatrick, D., Lund, J. S., Schmechel, D. E., and Towles, A. C. (1987). Distribution of GABAergic neurons and axon terminals in the macaque striate cortex. J. Comp. Neurol. 264, 73-91. doi: 10.1002/cne.902640107

Gabbott, P. L., and Bacon, S. J. (1996). Local circuit neurons in the media prefrontal cortex (areas 24a,b,c, 25, and 32) in the monkey: II. Quantitative areal and laminar distributions. J. Comp. Neurol. 364, 609-636. doi: 10.1002/(SICI) 1096-9861(19960122)364:4<609::AID-CNE2>3.0.CO;2-7

Gabbott, P. L., Dickie, B. G., Vaid, R. R., Headlam, A. J., and Bacon, S. J. (1997). Local-circuit neurones in the medial prefrontal cortex (areas 25, 32, and 24b) in the rat: morphology and quantitative distribution. J. Comp. Neurol. 377, 465-499. doi: 10.1002/(SICI) 1096-9861(19970127)377:4<465::AID-CNE1>3.0.CO;2-0

Goldman-Rakic, P. S. (1999). The "psychic" neuron of the cerebral cortex. Ann. N. Y. Acad. Sci. 868, 13-26. doi: 10.1111/j.1749-6632.1999. tb11270.x

Gonchar, Y., and Burkhalter, A. (1997). Three distinct families of GABAergic neurons in rat visual cortex. Cereb. Cortex 7, 347-358. doi: 10.1093/cercor/7.4.347

Gonchar, Y., Wang, Q., and Burkhalter, A. (2007). Multiple distinct subtypes of GABAergic neurons in mouse visual cortex identified by triple immunostaining Front. Neuroanat. 1:3. doi: 10.3389/neuro.05.003.2007

Groenewegen, H. J., and Uylings, H. B. (2000). The prefrontal cortex and the integration of sensory, limbic and autonomic information. Prog. Brain Res. 126, 3-28. doi: 10.1016/S0079-6123(00)26003-2

Gulyas, A. I., Szabo, G. G., Ulbert, I., Holderith, N., Monyer, H., Erdelyi, F., et al. (2010). Parvalbumin-containing fast-spiking basket cells generate the field potential oscillations induced by cholinergic receptor activation in the hippocampus. J. Neurosci. 30, 15134-15145. doi: 10.1523/JNEUROSCI.410410.2010

Harris, K. D., Csicsvari, J., Hirase, H., Dragoi, G., and Buzsaki, G. (2003). Organization of cell assemblies in the hippocampus. Nature 424, 552-556. doi: 10.1038 /nature01834

Hendry, S. H., Schwark, H. D., Jones, E. G., and Yan, J. (1987). Numbers and proportions of GABA-immunoreactive neurons in different areas of monkey cerebral cortex. J. Neurosci. 7, 1503-1519.

Hladnik, A., Džaja, D., Darmopil, S., Jovanov Miloševic, N., and Petanjek, Z. (2014). Spatio-temporal extension in site of origin for cortical calretinin neurons in primates. Front. Neuroanat. 8:50. doi: 10.3389/fnana.2014.00050

Hofman, M. A. (2014). Evolution of the human brain: when bigger is better. Front Neuroanat. 8:15. doi: 10.3389/fnana.2014.00015

Hornung, J. P., and De Tribolet, N. (1994). Distribution of GABA-containing neurons in human frontal cortex: a quantitative immunocytochemical study. Anat. Embryol. (Berl) 189, 139-145. doi: 10.1007/BF00185772

Jacot-Descombes, S., Uppal, N., Wicinski, B., Santos, M., Schmeidler, J., Giannakopoulos, P., et al. (2012). Decreased pyramidal neuron size in Brodmann areas 44 and 45 in patients with autism. Acta Neuropathol. 124, 67-79 doi: 10.1007/s00401-012-0976-6

Jiang, X., Wang, G., Lee, A. J., Stornetta, R. L., and Zhu, J. J. (2013). The organization of two new cortical interneuronal circuits. Nat. Neurosci. 16, 210-218. doi: 10.1038/nn.3305

Jones, E. G., Huntley, G. W., and Benson, D. L. (1994). Alpha calcium/calmodulindependent protein kinase II selectively expressed in a subpopulation of excitatory neurons in monkey sensory-motor cortex: comparison with GAD-67 expression. J. Neurosci. 14, 611-629.

Kubota, Y., Hattori, R., and Yui, Y. (1994). Three distinct subpopulations of GABAergic neurons in rat frontal agranular cortex. Brain Res. 649, 159-173. doi: 10.1016/0006-8993(94)91060-X

Lin, C. S., Lu, S. M., and Schmechel, D. E. (1986). Glutamic acid decarboxylase and somatostatin immunoreactivities in rat visual cortex. J. Comp. Neurol. 244, 369-383. doi: 10.1002/cne.902440309

Ma, T., Wang, C., Wang, L., Zhou, X., Tian, M., Zhang, Q., et al. (2013). Subcortical origins of human and monkey neocortical interneurons. Nat. Neurosci. 16, 15881597. doi: $10.1038 / \mathrm{nn} .3536$

Markram, H., Toledo-Rodriguez, M., Wang, Y., Gupta, A., Silberberg, G., and Wu, C. (2004). Interneurons of the neocortical inhibitory system. Nat. Rev. Neurosci. 5, 793-807. doi: 10.1038/nrn1519

Meinecke, D. L., and Peters, A. (1987). GABA immunoreactive neurons in rat visual cortex. J. Comp. Neurol. 261, 388-404. doi: 10.1002/cne.902610305

Melchitzky, D. S., Eggan, S. M., and Lewis, D. A. (2005). Synaptic targets of calretinin-containing axon terminals in macaque monkey prefrontal cortex. Neuroscience 130, 185-195. doi: 10.1016/j.neuroscience.2004.08.046

Melchitzky, D. S., and Lewis, D. A. (2003). Pyramidal neuron local axon terminals in monkey prefrontal cortex: differential targeting of subclasses of GABA neurons. Cereb. Cortex 13, 452-460. doi: 10.1093/cercor/13.5.452

Meskenaite, V. (1997). Calretinin-immunoreactive local circuit neurons in area 17 of the cynomolgus monkey, Macaca fascicularis. J. Comp. Neurol. 379, 113-132. doi: 10.1002/(SICI) 1096-9861(19970303)379:1 < 113::AID-CNE8 > 3.0.CO;2-7

Micheva, K. D., and Beaulieu, C. (1995). Postnatal development of GABA neurons in the rat somatosensory barrel cortex: a quantitative study. Eur. J. Neurosci. 7, 419-430. doi: 10.1111/j.1460-9568.1995.tb00338.x

Morrison, J. H., and Hof, P. R. (2002). Selective vulnerability of corticocortical and hippocampal circuits in aging and Alzheimer's disease. Prog. Brain Res. 136, 467-486. doi: 10.1016/S0079-6123(02)36039-4

Nieuwenhuys, R. (1994). The neocortex. An overview of its evolutionary development, structural organization and synaptology. Anat. Embryol. (Berl) 190, 307-337.

Petanjek, Z., Judas, M., Kostovic, I., and Uylings, H. B. (2008). Lifespan alterations of basal dendritic trees of pyramidal neurons in the human prefrontal cortex: a layer-specific pattern. Cereb. Cortex 18, 915-929. doi: 10.1093/cercor/bhm124

Petanjek, Z., Judas, M., Simic, G., Rasin, M. R., Uylings, H. B., Rakic, P., et al. (2011). Extraordinary neoteny of synaptic spines in the human prefrontal cortex. Proc. Natl. Acad. Sci. U.S.A. 108, 13281-13286. doi: 10.1073/pnas.1105108108

Petanjek, Z., and Kostovic, I. (2012). Epigenetic regulation of fetal brain development and neurocognitive outcome. Proc. Natl. Acad. Sci. U.S.A. 109, 11062-11063. doi: 10.1073/pnas.1208085109 
Peters, A., and Kimerer, L. M. (1981). Bipolar neurons in rat visual cortex: a combined Golgi-electron microscope study. J. Neurocytol. 10, 921-946. doi: 10.1007/BF01258522

Petrides, M., Tomaiuolo, F., Yeterian, E. H., and Pandya, D. N. (2012). The prefrontal cortex: comparative architectonic organization in the human and the macaque monkey brains. Cortex 48, 46-57. doi: 10.1016/j.cortex.2011.07.002

Pfeffer, C. K., Xue, M., He, M., Huang, Z. J., and Scanziani, M. (2013). Inhibition of inhibition in visual cortex: the logic of connections between molecularly distinct interneurons. Nat. Neurosci. 16, 1068-1076. doi: 10.1038/nn.3446

Pouille, F., and Scanziani, M. (2004). Routing of spike series by dynamic circuits in the hippocampus. Nature 429, 717-723. doi: 10.1038/nature02615

Rajkowska, G., and Goldman-Rakic, P. S. (1995a). Cytoarchitectonic definition of prefrontal areas in the normal human cortex: I. Remapping of areas 9 and 46 using quantitative criteria. Cereb. Cortex 5, 307-322. doi: 10.1093/cercor/ 5.4 .307

Rajkowska, G., and Goldman-Rakic, P. S. (1995b). Cytoarchitectonic definition of prefrontal areas in the normal human cortex: II. Variability in locations of areas 9 and 46 and relationship to the Talairach Coordinate System. Cereb. Cortex 5, 323-337. doi: 10.1093/cercor/5.4.323

Rakic, P. (2009). Evolution of the neocortex: a perspective from developmental biology. Nat. Rev. Neurosci. 10, 724-735. doi: 10.1038/nrn2719

Ren, J. Q., Aika, Y., Heizmann, C. W., and Kosaka, T. (1992). Quantitative analysis of neurons and glial cells in the rat somatosensory cortex, with special reference to GABAergic neurons and parvalbumin-containing neurons. Exp. Brain Res. 92, 1-14. doi: 10.1007/BF00230378

Santana, N., Bortolozzi, A., Serrats, J., Mengod, G., and Artigas, F. (2004). Expression of serotonin $1 \mathrm{~A}$ and serotonin2A receptors in pyramidal and GABAergic neurons of the rat prefrontal cortex. Cereb. Cortex 14, 1100-1109. doi: 10.1093/cercor/bhh070

Schwaller, B. (2014). Calretinin: from a "simple" $\mathrm{Ca}^{2+}$ buffer to a multifunctional protein implicated in many biological processes. Front. Neuroanat. 8:3. doi: 10.3389/fnana.2014.00003

Selemon, L. D., Ceritoglu, C., Ratnanather, J. T., Wang, L., Harms, M. P., Aldridge, K., et al. (2013). Distinct abnormalities of the primate prefrontal cortex caused by ionizing radiation in early or midgestation. J. Comp. Neurol. 521, 1040-1053. doi: $10.1002 / \mathrm{cne} .23217$

Selemon, L. D., Mrzljak, J., Kleinman, J. E., Herman, M. M., and Goldman-Rakic, P. S. (2003). Regional specificity in the neuropathologic substrates of schizophrenia: a morphometric analysis of Broca's area 44 and area 9. Arch. Gen. Psychiatry 60, 69-77. doi: 10.1001/archpsyc.60.1.69

Shepherd, G. M. (2011). The microcircuit concept applied to cortical evolution: from three-layer to six-layer cortex. Front. Neuroanat. 5:30. doi: 10.3389/fnana.2011.00030

Sherwood, C. C., Holloway, R. L., Erwin, J. M., and Hof, P. R. (2004). Cortical orofacial motor representation in Old World monkeys, great apes, and humans. II. Stereologic analysis of chemoarchitecture. Brain Behav. Evol. 63, 82-106. doi $10.1159 / 000075673$

Sherwood, C. C., Holloway, R. L., Semendeferi, K., and Hof, P. R (2005). Is prefrontal white matter enlargement a human evolutionary specialization? Nat. Neurosci. 8, 537-538; author reply 538. doi: 10.1038/ nn0505-537

Somogyi, P., Katona, L., Klausberger, T., Lasztoczi, B., and Viney, T. J. (2014). Temporal redistribution of inhibition over neuronal subcellular domains underlies state-dependent rhythmic change of excitability in the hippocampus. Philos. Trans. R. Soc. Lond. B Biol. Sci. 369:20120518. doi: 10.1098/rstb. 2012.0518

Spocter, M. A., Hopkins, W. D., Barks, S. K., Bianchi, S., Hehmeyer, A. E. Anderson, S. M., et al. (2012). Neuropil distribution in the cerebral cortex differs between humans and chimpanzees. J. Comp. Neurol. 520, 2917-2929. doi: $10.1002 / \mathrm{cne} .23074$

Spruston, N. (2008), Pyramidal neurons: dendritic structure and synaptic integration. Nat. Rev. Neurosci. 9, 206-221. doi: 10.1038/nrn2286
Tamamaki, N., Yanagawa, Y., Tomioka, R., Miyazaki, J., Obata, K., and Kaneko, T. (2003). Green fluorescent protein expression and colocalization with calretinin, parvalbumin, and somatostatin in the GAD67-GFP knock-in mouse. J. Comp. Neurol. 467, 60-79. doi: 10.1002/cne.10905

Teffer, K., and Semendeferi, K. (2012). Human prefrontal cortex: evolution, development, and pathology. Prog. Brain Res. 195, 191-218. doi: 10.1016/B9780-444-53860-4.00009-X

Toledo-Rodriguez, M., Blumenfeld, B., Wu, C., Luo, J., Attali, B., Goodman, P., et al. (2004). Correlation maps allow neuronal electrical properties to be predicted from single-cell gene expression profiles in rat neocortex. Cereb. Cortex 14, 13101327. doi: 10.1093/cercor/bhh092

Uematsu, M., Hirai, Y., Karube, F., Ebihara, S., Kato, M., Abe, K., et al. (2008). Quantitative chemical composition of cortical GABAergic neurons revealed in transgenic venus-expressing rats. Cereb. Cortex 18, 315-330. doi: $10.1093 /$ cercor/bhm056

Uylings, H. B., and van Eden, C. G. (1990). Qualitative and quantitative comparison of the prefrontal cortex in rat and in primates, including humans. Prog. Brain Res. 85, 31-62. doi: 10.1016/S0079-6123(08)62675-8

Verduzco-Flores, S., Bodner, M., Ermentrout, B., Fuster, J. M., and Zhou, Y. (2009). Working memory cells' behavior may be explained by cross-regional networks with synaptic facilitation. PLoS ONE 4:e6399. doi: 10.1371/journal.pone.0006399

Wang, Y., Markram, H., Goodman, P. H., Berger, T. K., Ma, J., and Goldman-Rakic, P. S. (2006). Heterogeneity in the pyramidal network of the medial prefrontal cortex. Nat. Neurosci. 9, 534-542. doi: 10.1038/nn1670

Wang, Y., Toledo-Rodriguez, M., Gupta, A., Wu, C., Silberberg, G., Luo, J., et al. (2004). Anatomical, physiological and molecular properties of Martinotti cells in the somatosensory cortex of the juvenile rat. J. Physiol. 561, 65-90. doi: 10.1113/jphysiol.2004.073353

Xu, X., Roby, K. D., and Callaway, E. M. (2010). Immunochemical characterization of inhibitory mouse cortical neurons: three chemically distinct classes of inhibitory cells. J. Comp. Neurol. 518, 389-404. doi: 10.1002/cne.22229

Yan, Y. H., Van Brederode, J. F., and Hendrickson, A. E. (1995). Developmental changes in calretinin expression in GABAergic and nonGABAergic neurons in monkey striate cortex. J. Comp. Neurol. 363, 78-92. doi: 10.1002/cne.903630108

Yanez, I. B., Munoz, A., Contreras, J., Gonzalez, J., Rodriguez-Veiga, E., and DeFelipe, J. (2005). Double bouquet cell in the human cerebral cortex and a comparison with other mammals. J. Comp. Neurol. 486, 344-360. doi: 10.1002/cne.20533

Yeterian, E. H., Pandya, D. N., Tomaiuolo, F., and Petrides, M. (2012). The cortical connectivity of the prefrontal cortex in the monkey brain. Cortex 48, 58-81. doi: 10.1016/j.cortex.2011.03.004

Zaitsev, A. V., Gonzalez-Burgos, G., Povysheva, N. V., Kroner, S., Lewis, D. A., and Krimer, L. S. (2005). Localization of calcium-binding proteins in physiologically and morphologically characterized interneurons of monkey dorsolateral prefrontal cortex. Cereb. Cortex 15, 1178-1186. doi: 10.1093/cercor/ bhh 218

Conflict of Interest Statement: The authors declare that the research was conducted in the absence of any commercial or financial relationships that could be construed as a potential conflict of interest.

Received: 01 May 2014; accepted: 07 September 2014; published online: 25 September 2014.

Citation: Džaja D, Hladnik A, Bičanić I, Baković M and Petanjek Z (2014) Neocortical calretinin neurons in primates: increase in proportion and microcircuitry structure. Front. Neuroanat. 8:103. doi: 10.3389/fnana.2014.00103

This article was submitted to the journal Frontiers in Neuroanatomy.

Copyright (c) 2014 Džaja, Hladnik, Bičanić, Baković and Petanjek. This is an openaccess article distributed under the terms of the Creative Commons Attribution License (CC BY). The use, distribution or reproduction in other forums is permitted, provided the original author(s) or licensor are credited and that the original publication in this journal is cited, in accordance with accepted academic practice. No use, distribution or reproduction is permitted which does not comply with these terms. 